\title{
CHEBI ID
}

National Cancer Institute

\section{Source}

National Cancer Institute. CHEBI ID. NCI Thesaurus. Code C98965.

Indicates that a concept in the 'Drug, Food, Chemical or Biomedical Material' branch of the $\mathrm{NCl}$ thesaurus maps to a specific concept in the EBI Chemical Entities of Biological Interest database. 